\title{
Research on residual shear strength of surrounding rock base on elastic-plastic softening model
}

\author{
Heng Zhou ${ }^{1,2}$, Ying Zhang ${ }^{1,2}$, Bo Liu ${ }^{1}$, Shengjie Di ${ }^{1,2^{*}}$ and Peng Huang ${ }^{1,2}$ \\ ${ }^{1}$ Northwest Engineering Corporation Limited, Power China, Xi'an, Shanxi, 710065, China \\ ${ }^{2}$ High Slope and Geological Hazard Research \& Management branch, National Energy and Hydropower \\ Engineering Technology R\&D Center, Xi’an, Shanxi, 710065, China
}

\begin{abstract}
With the rapid development of infrastructure construction, the edge shape analysis of underground chamber excavation in water conservancy and hydropower projects has received more and more attention. This paper takes an underground chamber of a hydropower project as the research object and uses an ideal elastoplastic stress-strain softening model to study the relationship between deformation, stress, plastic zone and strength parameters. The results show that the value of each shear strength parameter has a significant effect on the distance of the plastic zone, and the calculation result may provide a basis for the design.
\end{abstract}

\section{Introduction}

In the fields of water conservancy and hydropower engineering, underground water storage engineering, etc., it involves reasonable support design for underground cavern excavation [1]. Especially the underground powerhouse caverns of hydropower stations in mountainous and valley areas have the characteristics of large caverns, large buried depths and complex geological conditions. The stability and safety of the surrounding rock are outstanding [2,3]. The deformation and failure of the surrounding rock of large underground caverns mainly occurs under the action of rebound stress and redistributed stress caused by excavation unloading. There is no unified standard for the stability criterion of surrounding rock of caverns. The main reason is that the conditions encountered in the actual project are too complicated. The nature of the rock mass, the size and shape of the cavern, the size of the stress conditions (the initial stress of the rock mass), and even the construction method will affect it. The combination of these factors is unpredictable. In some cavern projects, the convergence of the circumference of the cave exceeded the allowable value by several times, and no instability occurred. Some projects (especially shallow buried projects) did not reach the allowable value, but instability and collapse accident occurred.

The large-scale excavation of underground rock mass will inevitably lead to the adjustment of the stress field of the surrounding rock, resulting in unloading of the surrounding rock within a certain range. During the unloading failure process, the deformation and strength parameters of the rock mass are significantly weakened [4] In general, elastoplastic numerical analysis, the rock mass parameter is always a constant in the calculation process. Then it is necessary to consider the weakening of rock mass strength parameters during unloading failure. Constitutive model is one of the important contents in the study of rock mechanics. The stress-strain relation curve of rock can be approximately linear at the beginning, that is, the elastic property of rock [5].

\section{Constitutive model}

The curve of the ideal elastoplastic softening model is shown in Figure 1. The stress-strain curve first enters the elastic stage, and after the growth reaches the peak, it enters the yield platform along the peak strength, which is the ideal state, and enters the yield platform along the residual strength as the softened state. Therefore, the influence of multiple combined stress paths can be fully considered.

For underground engineering, an appropriate constitutive relationship should be selected to describe the characteristics of the rock. The ideal model usually used will cause the strength of the surrounding rock in the plastic area to be overestimated. In this calculation, the softening model is selected, and the strength of the surrounding rock in the plastic zone is taken as the participating strength, which can better reflect the actual situation of chamber excavation.

*Corresponding author's e-mail:14276804@qq.com 


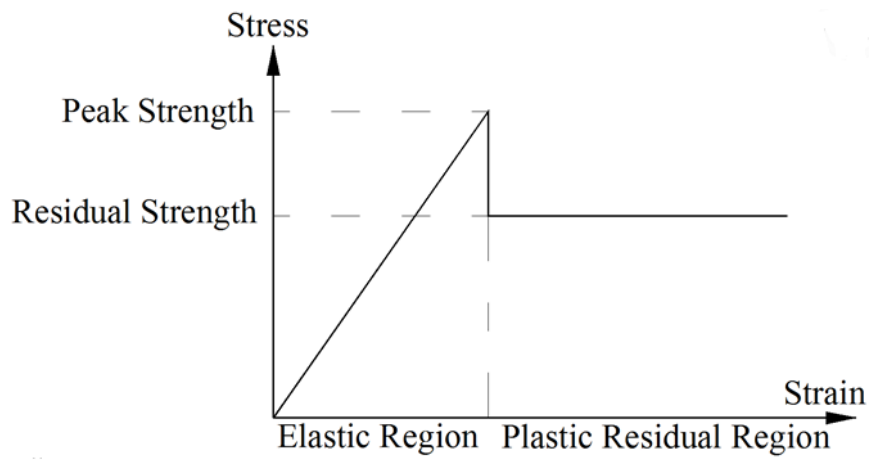

Figure 1. Ideal elastic-plastic softening model

\section{Calculation analysis and sensitivity analysis}

The power station hub is mainly composed of upper reservoir, lower reservoir, water delivery system, underground powerhouse, switch station and other buildings. The underground powerhouse caverns are placed at the tail of the water conveyance system, and the overlying rock mass is about $300-480 \mathrm{~m}$ thick. The lithology is slightly weathered granodiorite, with medium and low in-situ stress, and the surrounding rocks are mainly of type II to III. In the main cavern, the outline size of the underground powerhouse excavation is
$177.5 \times 25.5 \times 57.5 \mathrm{~m} \quad($ length $\times$ width $\times$ height $)$, and the outline size of the main transformer tunnel is $153.5 \mathrm{~m} \times 19.5 \mathrm{~m} \times 21.8 \mathrm{~m}$, the outline size of the tail gate tunnel excavation is $122.4 \times 8 \times 20.3 \mathrm{~m}$.

The cavern concludes main power house, maintransformed cavern and tailrace surge chamber, and excavated in layer and blocks. The main powerhouse and chamber is excavated in 8 layers. Except for the roof arch layer, the height of the layers is $5 \sim 8 \mathrm{~m}$. The main variable cave is divided into four floors. The tailgate hole is mainly excavated in 4 layers, the lower tail water branch pipe is excavated in 5 layers, and the calculation model is shown in Figure 2. The mechanical parameters for sensitivity analysis are shown in Figure 3.

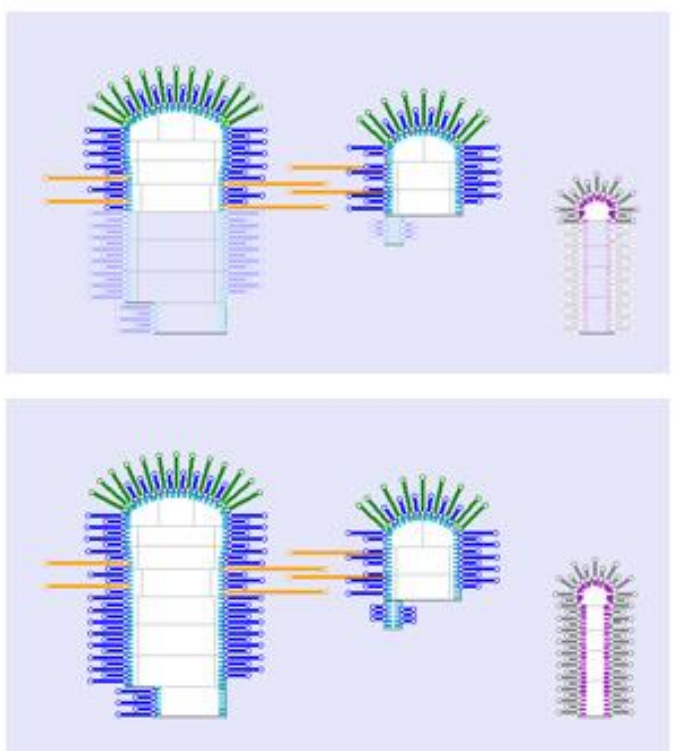

Figure 2. Calculation model

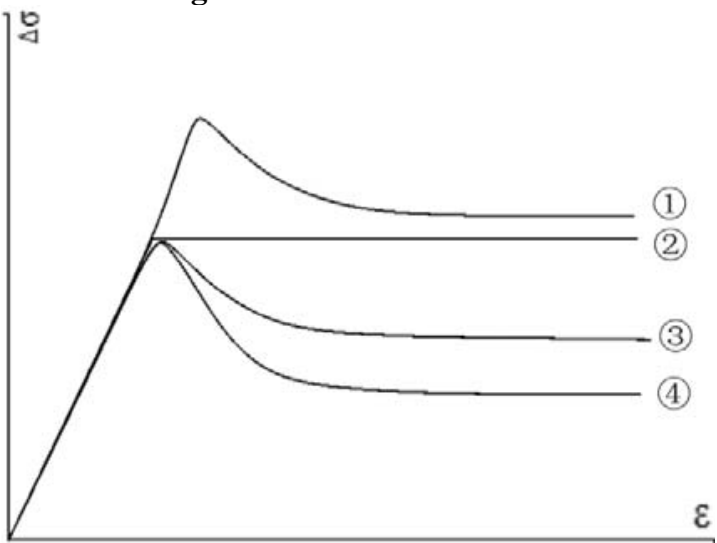

Figure 3. Mechanical parameters for sensitivity analysis 
The stress-strain softening model was adopted to take dynamic parameter values, and the calculation results were shown in Figure 4. The yield area of the right wall of the main workshop near the arch roof was relatively large, so the support needed to be strengthened. By comparing the calculation results of the four types of surrounding rocks, the range of yield zone is positively correlated with the types of surrounding rocks, and the higher the parameters of surrounding rocks, the smaller the yield range.
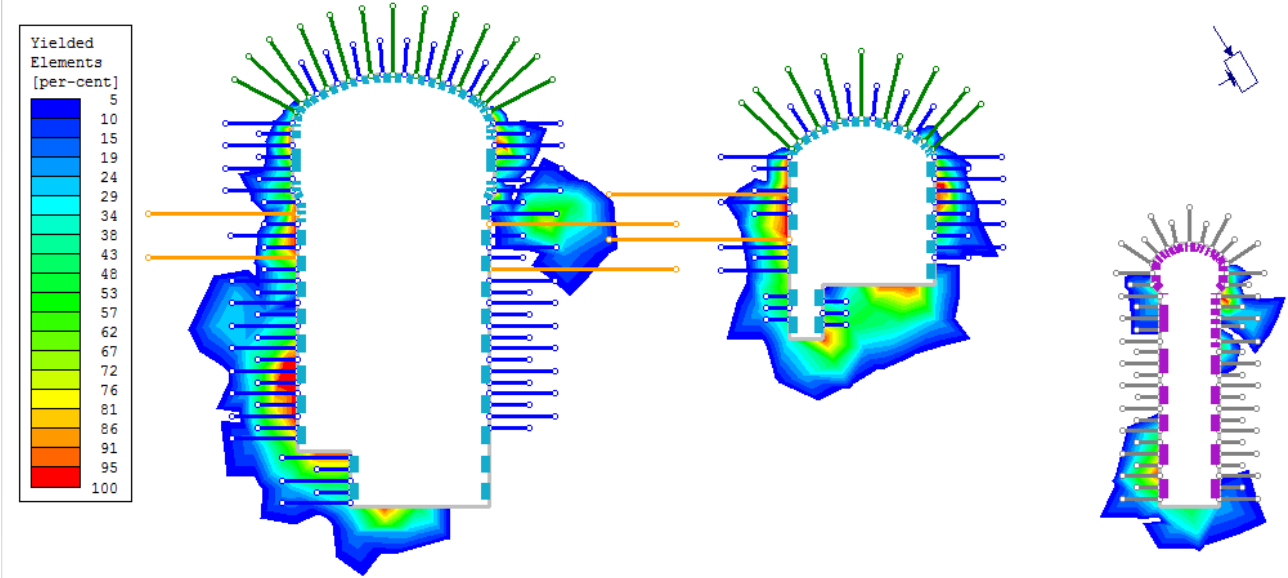

Figure 4. Yield zone contour

From the calculation results (Figure 5 and Figure 6), the left wall of main power house in step 8 excavation exposed displacement inflection point, with the implement of the subsequent excavation. The displacement increases gradually, the four categories of laws of surrounding rock, and the calculation of deformation values change, the trend of curve steepened gradually shows that the strength of the peak after peak strength, the effect is more apparent. And with the decrease of parameters of the attenuation law of acceleration.

The comparison of the plastic zone distance between the calculated parameters shows that the influence of the strength parameters on the plastic zone distance is obvious, and the influence on the arch roof is the greatest.

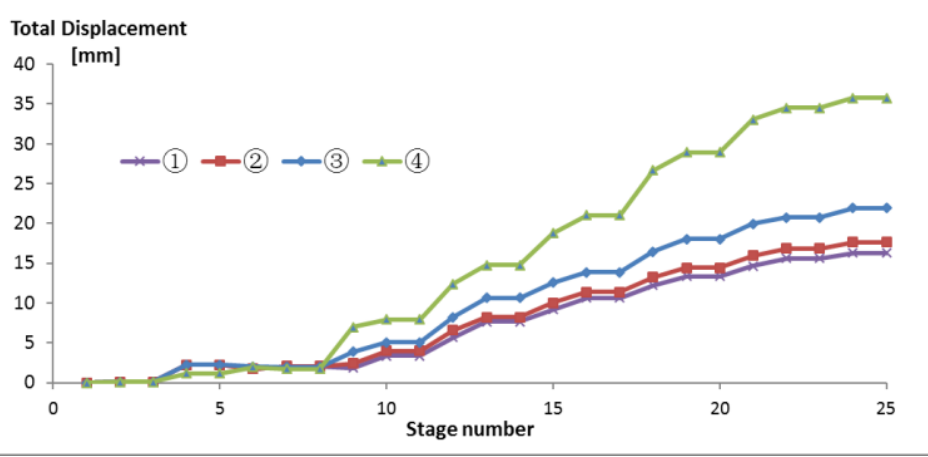

Figure 5. Total displacement with calculation step variation curve

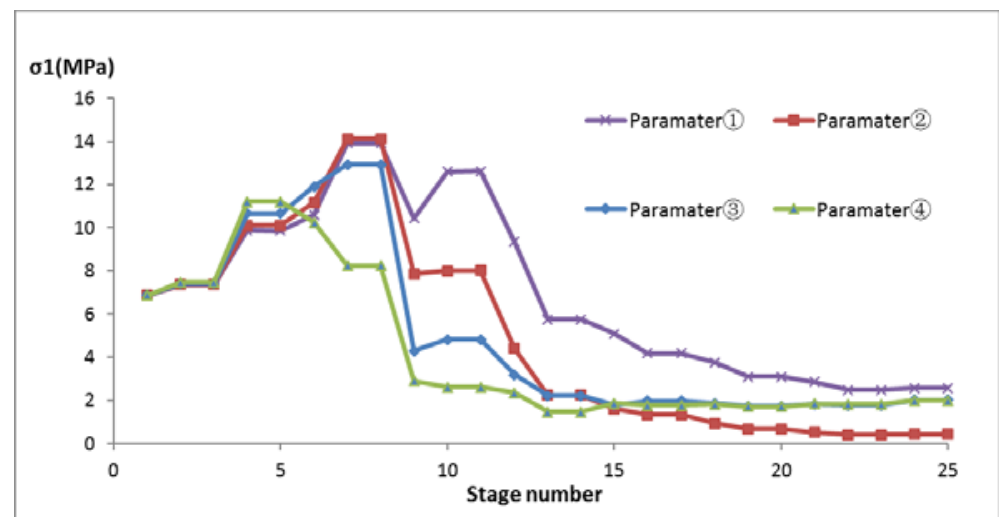

Figure 6. Major principal stress with calculation step variation curve 


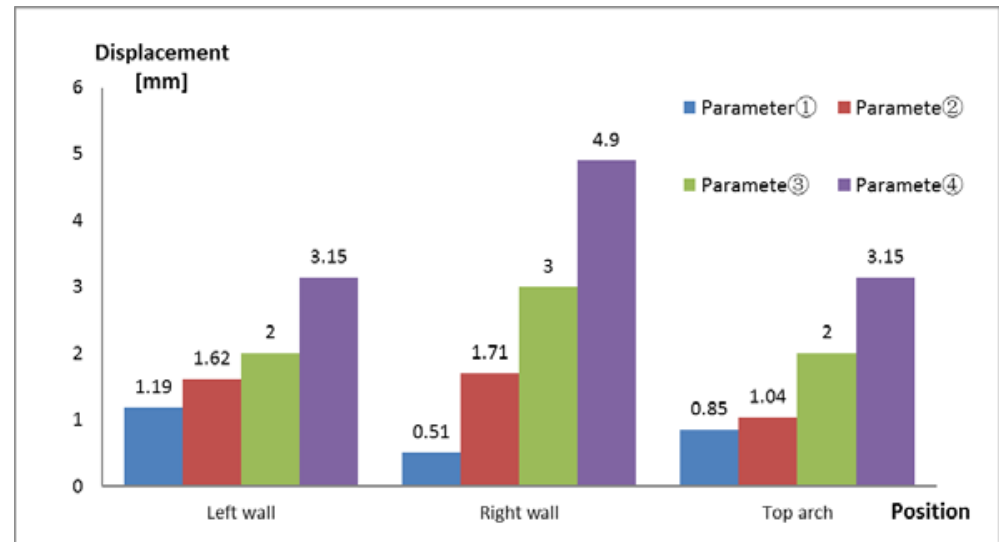

Figure 7. Comparison of calculation parameters and displacement

The parameters of sensitivity calculation is shown in Table 1. And the results (Figure 8) show that the internal

friction angle, residual internal friction angle and residual

Table 1. Sensitivity analysis calculation planes

\begin{tabular}{cccccc}
\hline Numerical procedure & $\begin{array}{c}\text { Peak internal } \\
\text { friction angle }\left({ }^{\circ}\right)\end{array}$ & $\begin{array}{c}\text { Peak cohesion } \\
(\mathrm{MPa})\end{array}$ & $\begin{array}{c}\text { Residual internal } \\
\text { friction angle }\left(^{\circ}\right)\end{array}$ & $\begin{array}{c}\text { Residual } \\
\text { cohesion } \\
(\mathrm{MPa})\end{array}$ \\
\hline \multirow{3}{*}{ Plan1 } & Plan 1-1 & $53(+6 \%)$ & 1.50 & 40 & 1.20 \\
& Plan 1-2 & $50(+0 \%)$ & 1.50 & 40 & 1.20 \\
& Plan 1-3 & $45(-10 \%)$ & 1.50 & 40 & 1.20 \\
\multirow{3}{*}{ Plan2 } & Plan 2-1 & 50 & $1.60(+6 \%)$ & 40 & 1.20 \\
& Plan 2-2 & 50 & $1.50(+0 \%)$ & 40 & 1.20 \\
& Plan 2-3 & 50 & $1.35(-10 \%)$ & 40 & 1.20 \\
& Plan 3-1 & 50 & 1.50 & $42(+6 \%)$ & 1.20 \\
& Plan 3-2 & 50 & 1.50 & $40(+0 \%)$ & 1.20 \\
& Plan 3-3 & 50 & 1.50 & $36(-10 \%)$ & 1.20 \\
& Plan 4-1 & 50 & 1.50 & 40 & $1.20(+6 \%)$ \\
& Plan 4-2 & 50 & 1.50 & 40 & $1.08(-10 \%)$ \\
\hline
\end{tabular}

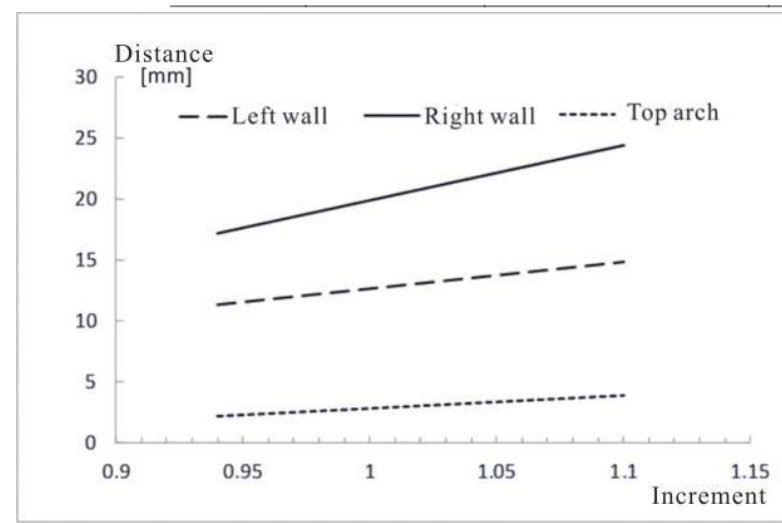

(1) Plan 1

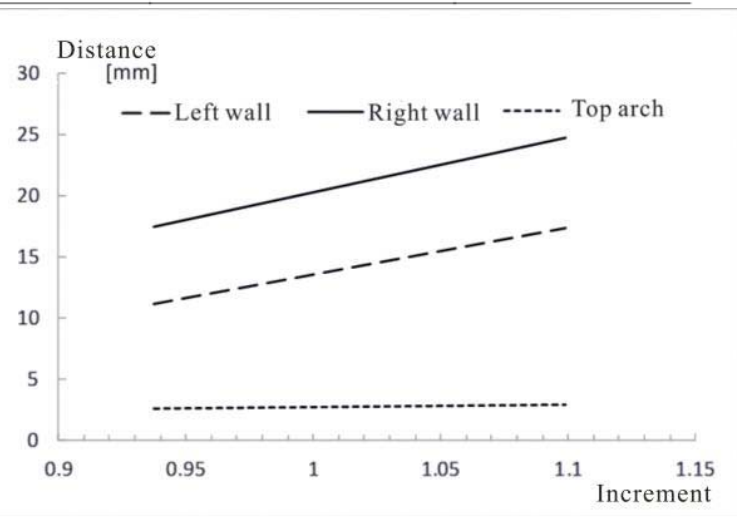

(2) Plan 3

Figure 8. Plastic zone distance with residual friction angle sensitivity curve

\section{Conclusion}

(1) By using the ideal elastic-plastic stress-strain softening model, the excavation of the underground powerhouse is numerically calculated, and it is found that the right wall of the main powerhouse has the greatest deformation, the support there needs to be strengthened, and the difference in strength parameters has the greatest impact on the arch roof.

(2) The dynamic feedback adjustment of underground chamber excavation can be further carried out by comparing with the monitoring results to optimize the support system. 


\section{References}

1. Huang F., Zhu H., Xu Q., et al. (2013) The effect of weak interlayer on the failure pattern of rock mass around tunnel-Scaled model tests and numerical analysis. Tunnelling\&Underground Space Technology, 35(35): 207-218.

2. Wang S., Yin X., Tang H., et al. (2010) A new approach for analysing circular tunnel in strainsoften rock masses. International Journal of Rock Mechanics\&Mining Sciences, 47(1):170-178.

3. Zhang Q., Jiang B. S., Wang S. L., et al. (2012) Elastic-plastic analysis of a circular opening in strain-softening rock mass. International Journal of Rock Mechanics\&Mining Sciences, 50(1):38-46.

4. Lee Y. K., Pietruszczak S.. (2008) A new numerical procedure for elastic-plastic analysis of a circular opening excavated in a strain softening rock mass. Tunnelling and Underground Space Technology, 23(5): 588-599.

5. Alejano L. R., Alonso E., Rodriguez-Dono A., et al. (2010) Application of the convergence-confinement method to tunnels in rock masses exhibiting HoekBrown strain-softening behaviour. International Journal of Rock Mechanics\&Mining Sciences, 47(1):150-160. 